\title{
Yeast-based assays for the functional characterization of cancer-associated variants of human DNA repair genes
}

\author{
Tiziana Cervelli ${ }^{1}$, Samuele Lodovichi ${ }^{1}$, Francesca Bellè ${ }^{1}$ and Alvaro Galli ${ }^{1, *}$ \\ 1 Yeast Genetics and Genomics Group, Laboratory of Functional Genetics and Genomics, Institute of Clinical Physiology CNR, Via \\ Moruzzi 1, 56125 Pisa, Italy. \\ * Corresponding Author: \\ Alvaro Galli, Yeast Genetics and Genomics Group, Laboratory of Functional Genetics and Genomics, Institute of Clinical Physiology \\ CNR, Via Moruzzi 1, 56125 Pisa, Italy; E-mail: alvaro.galli@ifc.cnr.it
}

\begin{abstract}
Technological advances are continuously revealing new genetic variants that are often difficult to interpret. As one of the most genetically tractable model organisms, yeast can have a central role in determining the consequences of human genetic variation. DNA repair gene mutations are associated with many types of cancers, therefore the evaluation of the functional impact of these mutations is crucial for risk assessment and for determining therapeutic strategies. Owing to the evolutionary conservation of DNA repair pathways between human cells and the yeast Saccharomyces cerevisiae, several functional assays have been developed. Here, we describe assays for variants of human genes belonging to the major DNA repair pathways divided in functional assays for human genes with yeast orthologues and human genes lacking a yeast orthologue. Human genes with orthologues can be studied by introducing the correspondent human mutations directly in the yeast gene or expressing the human gene carrying the mutations; while the only possible approach for human genes without a yeast orthologue is the heterologous expression. The common principle of these approaches is that the mutated gene determines a phenotypic alteration that can vary according to the gene studied and the domain of the protein. Here, we show how the versatility of yeast can help in classifying cancer-associated variants.
\end{abstract}

doi: $10.15698 /$ mic2020.07.721

Received originally: 17.12.2019;

in revised form: 07.05.2020,

Accepted 13.05.2020,

Published 18.05.2020.

Keywords: Saccharomyces cerevisiae, human DNA repair genes, cancer-associated variants, functional assays, humanized yeast strains.

\begin{abstract}
Abbreviations:
BER - base excision repair; BRCT - BRCA1 Cterminus; DDR - DNA damage repair; DSB double strand break; ENGIMA - Evidence - based Network for the Interpretation of Germline Mutant Alleles; $\boldsymbol{F S}$ - functional score; GR - gene reversion; $\mathrm{HBOC}$ - breast and ovarian cancer syndrome; HNPCC - hereditary nonpolyposis colorectal cancer; HR - homologous recombination; InSiGHT - International Society for Gastrointestinal Hereditary Tumours; MAVE multiplexed assay of variant effect; MMR mismatch repair; MMS - methyl methane sulfonate; NER - nucleotide excision repair; NGS next generation sequencing; NHEJ - nonhomologous end joining; Pol - polymerase; PRR post-replication repair; $\mathbf{R S}$ - reliability score; $\mathbf{S C P}$ - small colony phenotype; TA - transcription activation; VUS - variant of unknown significance; WT - wild type; YLP - yeast localization phenotype.
\end{abstract}

\section{DNA REPAIR AND CANCER}

Genomic instability is an enabling trait for cancer development. The main factor determining genome instability is the alteration of the DNA damage response (DDR) [1]. DDR has a pivotal role in the protection of DNA from endogenous and environmental damage. DDR is composed of proteins sensing DNA damage, proteins responsible for the activation of checkpoints allowing the cells to repair DNA before entering $S$ phase, and proteins actively involved in DNA repair. To cope with the different types of DNA dam- age, cells are equipped with several specialized DNA repair pathways: Base Excision Repair (BER), Mismatch Repair (MMR), Nucleotide Excision Repair (NER), Homologous Recombination (HR) and Non-Homologous End Joining (NHEJ) $[2,3]$. BER is responsible for sensing and repairing DNA single-strand breaks (SSB). MMR is involved in repairing unsuitable insertions, deletions, and single nucleotide mismatched incorporation. The NER pathway corrects DNA adducts or UV-dimers induced by ultraviolet radiations. HR and NHEJ pathways play a major role in processing and 
repairing DNA double strand breaks (DSB) [4]. Moreover, during DNA replication, when the replication fork encounters a lesion in the DNA template and it is stalled, the postreplication repair (PRR) pathway allows to bypass the DNA damage and consequently to complete DNA replication [5].

Mutations in DNA repair genes may impact on cancer differently: they may predispose to cancer (cancer susceptibility genes), affect tumor progression or drug sensitivity of cancer cells. The present review is focused on DNA repair genes involved in cancer for which a functional yeastbased assay has been developed.

\section{Cancer predisposing mutations in DNA repair genes}

Cancer susceptibility genes are those identified as mutated in the germline, usually in heterozygosis. The best characterized familial cancers associated with DNA repair genes are Lynch syndrome (or hereditary nonpolyposis colorectal cancers, HNPCC) and breast and ovarian cancer syndrome (HBOC). HNPCC is caused by inactivating mutations in MMR genes such as MSH2, MSH6, MLH1, PMS1 and PMS2 while $\mathrm{HBOC}$ is caused by inactivating mutations in genes involved in HR such as BRCA1, BRCA2 [6, 7]. However, the advent of next generation sequencing (NGS) has allowed the identification of many germline polymorphisms in other genes playing a role in DNA repair that can be considered predisposing to cancer. HR genes such as RAD51, $R A D 52$, promoting DNA exchange and stimulating homologous pairing, respectively, have been reported to predispose to HBOC. Similarly, pathogenic variants of the NHEJ genes MRE11A and RAD50 may contribute to the risk of familial breast cancer [8]. Genetic polymorphisms in the NHEJ gene $X R C C 6 / K U 70$ are associated with several kinds of cancers; however, several contrasting results are reported and the effect of KU7O polymorphisms on cancer risk is still ambiguous [9].

Polymorphisms of the BER gene XRCC1 has been shown to be associated with colorectal, breast and ovarian cancer, prostate cancer, head and neck squamous cell carcinoma, pancreatic cancer [3]. Similarly, polymorphisms in NER genes have been identified in cancer types including lung and bladder [10]. The human homologue of the yeast gene $R A D 3$ named XPD/ERCC2 which encodes for a DNA helicase involved in NER [11, 12], has been demonstrated to be associated with several cancers [13].

Mutations in at least one of the MMR genes MSH2, MSH6, MLH1 and PMS1 have been found to be associated not only with HNPCC, but also with other cancer types such as breast, bladder and gastric cancer [14-17].

Fidelity of DNA replication before cell division is fundamental for genome integrity and for preventing tumor development [18]. The fidelity of DNA replication is mainly due to the proofreading activity of DNA polymerase $\delta$ (Pol $\delta$ ) and $\varepsilon$ (Pole), respectively Pol3 and Pol2 in yeast, that represent the principal polymerases involved in DNA replication. Besides their major role in DNA replication, Pol $\delta$ and Pole participate in BER, NER, MMR and DNA DSB repair [19]. Despite the great advances in DNA sequence technology, the association between DNA polymerase defects or increased mutation and cancer was established rather recently $[18,20]$. Mutations in POLD1 and POLE genes encoding the catalytic subunit of Pol $\delta$ and Pole, respectively, have been found in several types of cancer such as colorectal, endometrial, gastric and pancreatic cancer [18].

\section{Dysregulation of DNA repair genes and drug response}

During the transformation process, somatic mutations, epigenetic silencing and dysregulation of DNA repair genes can occur. These alterations can render the cells either more vulnerable or more resistant to DNA damaging cancer drugs. For instance, upregulation of DNA repair genes can determine resistance to DNA damaging treatments such as radiotherapy and some chemotherapeutic agents. One example of frequently up-regulated DNA repair gene is the HR gene RAD51. Its overexpression has been observed in leukemia, breast, and pancreatic cancers [21] $R A D 18$, an E3 ubiquitin-linked enzyme, has a role in maintaining genome stability through multiple DNA repair pathways, including HR and PPR [22-24]. Several studies have shown that high expression of RAD18 confers resistance to chemotherapy or radiotherapy in multiple human cancers [25-27]. Thus, targeted inhibition of DNA repair proteins could affect drug response and improve therapy efficacy $[28,29]$. Moreover, when a DNA repair pathway is downregulated, cancer cells can become dependent on an alternative pathway to repair DNA damage [30]. This could represent an advantage in terms of therapeutic efficacy, because it allows exploitation of the principle of synthetic lethality. Cancer cells depleted of both pathways would be unable to repair DNA damage, therefore treatment with inhibitors of the alternative pathway could be lethal for cancer cells [30].

Importantly, the HR gene RAD52 has been found to be synthetically lethal to the tumor suppressor gene $B R C A 2$; this represents an important finding to design more precise cancer therapies [31, 32].

\section{YEAST-BASED FUNCTIONAL ASSAYS ON DNA REPAIR HUMAN GENES}

NGS technology is making the sequencing of human genes very common in clinical genetics; this allows the identification of a large number of disease-associated mutations and thousands of polymorphisms in the human population [33]. Currently, the interpretation and assessment of the functional impact of disease-associated variants is a critical challenge [34, 35]. Genetic methods are often not informative due to the low frequency of the variant, which is, consequently, listed as "variant of unknown significance" (VUS). In hereditary cancer syndromes, the classification of the missense variants is urgently needed for risk assessment and to set up more precise therapies [36, 37]. One strategy to improve our knowledge on the functional impact of VUS is the use of functional assays. The purpose of functional assays is, not only, to classify and identify missense variants by assessing their impact on protein function, but also to correlate the biological function of the protein with its potential tumorigenic activity $[38,39]$. 
Moreover, direct assessment of the variants by functional assays using simple genetic systems can help in speeding up the evaluation of newly identified cancer-associated variants [38, 40-42]. Several assays have been developed in yeast and mammalian cell lines to evaluate the functional impact of cancer-related mutations of DNA repair genes; this review describes different kinds of yeast-based functional assays and discusses potential clinical applications.

Humans and the budding yeast Saccharomyces cerevisiae share thousands of protein-coding genes although they diverge by a billion years [43]. Interestingly, in several cases, the human gene can complement the deleted yeast gene [44]. Several reasons support the use of yeast as a model organism in cancer research. Yeast has contributed to the understanding of molecular mechanisms underlying cancer development through the discovery of crucial biological processes. Moreover, working with yeast is more economic compared to working with cell lines or animal models. Furthermore, construction of gene deletion strains, tagging proteins and site-specific mutagenesis are easier and faster than in human cells. Therefore, construction of "humanized" yeast, meaning a yeast strain expressing human genes or carrying mutation in an endogenous gene homologous to the human one, can be helpful in evaluating the functional consequences of human genetic variants found in several diseases [45-48]. When the yeast counterpart exists, functional assays can be developed by directly mutating the genomic copy of the yeast homologous gene (Figure 1A). Alternatively, the human gene or its orthologue can also be expressed from a plasmid (Figure 1B). Another approach implies the substitution of the yeast genomic copy with the corresponding human gene (Figure 1C). In the case of essential genes, the mutated gene has to be in heterozygosis; in haploid strains the wild type (WT) copy of the yeast gene is expressed from an episomal plasmid, in diploid strains, only one copy of the gene is

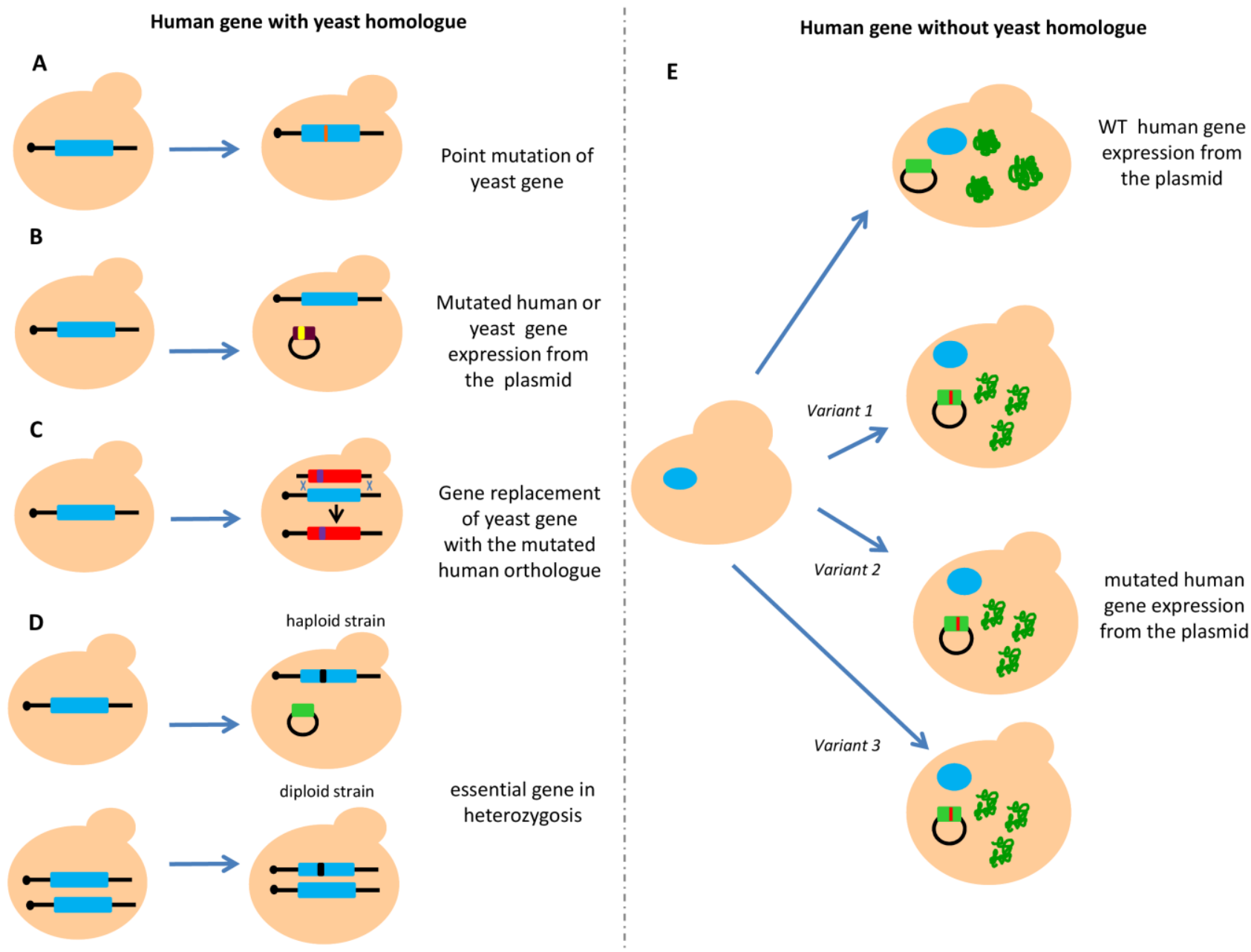

FIGURE 1: Constructions of humanized S. cerevisiae strains for functional analysis. Homology and complementation between yeast and human genes have to be considered for developing reliable functional assays. (A) When a yeast orthologue exists, yeast strains can be manipulated by directly inserting the mutation in the nucleotide corresponding to the human gene. (B) Mutants of human or yeast orthologous genes can be expressed from a plasmid. (C) Mutants of human or yeast orthologous genes can be replaced with the human counterpart. (D) In the case of an essential gene, functional analysis has to be evaluated in heterozygosis expressing the wild type form of the gene from a plasmid and mutating the endogenous one, or mutating one of the two alleles in a diploid strain. (E) When no homology between the human and yeast gene has been identified, the human gene is expressed from a plasmid. 
mutated (Figure 1D).When the yeast counterpart does not exist, the human gene is usually expressed from a centromeric or multicopy plasmid carrying the human copy under the control of a yeast constitutive or inducible promoter (Figure 1E).

Yeast functional assays are mainly based on direct comparison of the phenotype conferred by the mutated protein with that of the WT one. These assays could be more reliable if the phenotype assessed is consistent to the biological function(s) of the protein. To determine the functional impact of human DNA repair gene variants, currently available yeast assays are based on the evaluation of forward and reverse mutation, DNA damage sensitivity, transcriptional activity, growth defect, protein mislocalization, intra- and inter-chromosomal recombination (Table1). As shown in Table 1, assays for characterizing human DNA repair proteins belonging to any pathway have been developed in yeast.

\section{Strategies to study DNA repair genes conserved in yeast and humans}

The most attractive way to study the functional impact of cancer-related missense variants in human genes with an orthologue in yeast is to mutate native yeast genes to match the human sequences at the corresponding positions. This can be performed by aligning amino acid sequences of yeast and human proteins. To humanize specific positions within yeast genes, human and yeast genes have to share functional homology. Recently, we proposed a web tool that simultaneously finds the yeast homologous gene, identifies the corresponding variant(s) and determines the transferability of a human variant to the yeast counterpart by assigning a reliability score (RS) that may give helpful indications for potential accuracy of a functional assay to be developed [48]. The RS is assigned by an algorithm that computes functional data, type of mutation, amino acid conservation and chemistry of amino acid substitution. Mutations giving a positive RS are highly transferable to yeast and, therefore, yeast functional assays will be more reliable [48].

To our knowledge, study of the functional impact of mutated alleles that are localized in the native genome locus would be preferable to plasmid-based assays since gene expression is under the control of its natural promoter. This strategy has been exploited to study several DNA repair genes.

As the Rad51 and Rad52 protein sequences are highly conserved in human and S. cerevisiae, the functional impact of rare cancer-associated missense variants in both HR repair genes was evaluated by constructing yeast strains carrying correspondent mutated alleles (Figure 1A)[49]. A total of five predicted pathogenic variants, three located in the RAD51 and two in the RAD52 gene were analyzed in this study. Functional impact of the variants was evaluated by testing the sensitivity to DNA damaging agents and their effects on HR-mediated DSB repair (Figure 2A); three out of five variants studied conferred a hypersensitivity to methyl methane sulfonate (MMS) and defects in HR [49]. The effect of variants on HR has been studied by evaluating recombination intermediates and recombinants by onedimensional (1D) and two-dimensional (2D) gel electrophoresis of the HIS4LEU2 locus. This elegant approach has the limitation that it cannot be used for large scale analysis because its interpretation requires highly specialized expertise.

TABLE 1. DNA repair genes assayed in Saccharomyces cerevisiae.

\begin{tabular}{llll}
\hline Pathway & Human gene & Yeast gene & Functional Assay \\
\hline \multirow{2}{*}{ MMR } & MSH2 & MSH2 & Forward mutation [52], Reverse mutation [60] \\
\cline { 2 - 4 } & MLH1 & MLH1 & Forward mutation [51, 57, 59], Reverse mutation [56] \\
\hline \multirow{2}{*}{ HR } & RAD18 & RAD18 & UV, HU and MMS sensitivity [50] \\
\cline { 2 - 4 } & RAD51D & RAD51 & MMS sensitivity [49] \\
\cline { 2 - 4 } & BRCA1 & RAD52 & MMS sensitivity [49] \\
\cline { 2 - 4 } & BRCA2 & $/ /$ & TA [67, 70-72], SCP [63, 65, 75], YLP [64, 75], Liquid medium assay \\
\hline NHEJ & KU70/XRCC6 & YKU70 & Int, Intra- and Inter-chromosomal HR assay [65], GR assay [76, 77] \\
\hline NER & XPD/ERCC2 & RAD3 & UV, HU and MMS sensitivity [50] \\
\hline MMR, NER, & $P O L E$ & $P O L 2$ & Forward mutation [20] \\
\cline { 2 - 4 } BER, HR, NHEJ & $P O L D 1$ & $P O L 3$ & Forward mutation [61] \\
\hline
\end{tabular}

Several yeast-based assays have been developed to characterize human genes involved in Mismatch Repair (MMR), Homologous Recombination (HR), Post Replication Repair (PRR), Base and Nucleotide Excision Repair (BER, NER), and Non-Homologous End Joining (NHEJ). The name of the yeast and human gene is shown; BRCA1 and BRCA2 have no yeast homologue. TA, transcription activation assay; SCP, Small Colony Phenotype; YLP, Yeast Localization Phenotype; GR, gene reversion; MMS, methyl methane-sulfonate, HU hydroxyurea. 
Recently, several yeast strains carrying single nucleotide substitutions in RAD3, RAD18 and YKU7O corresponding to mutated alleles of the human ERCC2, RAD18 and $X R C C 6$ genes were constructed (Figure 1A) [50]. The functional impact of seven pathogenic variants (three located in the RAD3 gene, one in RAD18 and three in the YKU7O gene) was evaluated by determining the sensitivity to DNA damaging agents such as UV, MMS and hydroxyurea (HU) by spot assay and by measuring growth rate (Figure $2 \mathrm{~A}$ and 2B); two variants showed a functional defect [50]. This study represents a good example on how yeast assays can consolidate results obtained with prediction tools (e.g SIFT: https://sift.bii.a-star.edu.sg/ and PolyPhen-2: http://genetics.bwh.harvard.edu/pph2/), even if the num-

A Plate without treatment

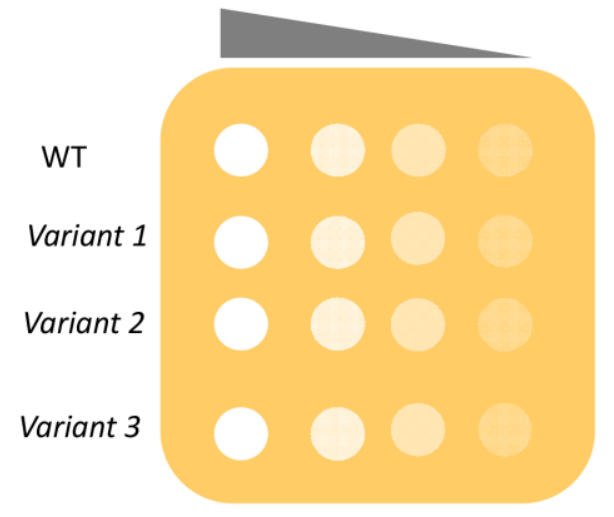

untreated

B

WT

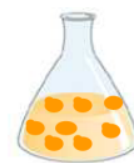

Variant 1

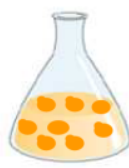

Variant 2

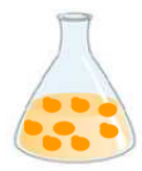

Variant 3

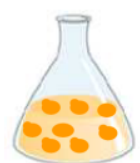

ber of variants analyzed is too few to be applied to genetic oncology.

Yeast strains carrying mutations corresponding to the homologous human gene or expressing the human variants have been exploited to evaluate the functional impact of variants located in the human MMR genes $h M L H 1$ and hMSH2 (Table 1, Figure 1B and 1C) [51-55]. One assay exploits the dominant-mutator effect that WT human MMR proteins have in MMR proficient yeast strain; in fact, the expression of $h M L H 1$ WT gene in yeast increases the spontaneous mutation rate measured by either a forward or reverse mutation assay. The mutator phenotype conferred to yeast by $h M L H 1$ WT is suppressed when a pathogenic variant is expressed [51]. By using a forward mutation as-

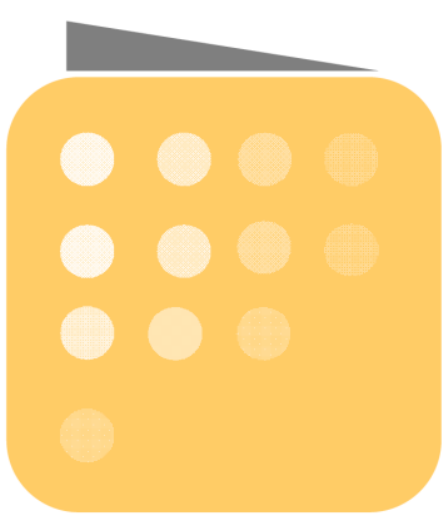

Spot assay

Treated with, MMS or HU or exposed to UV

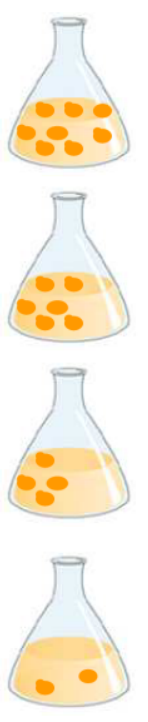

Growth rate

FIGURE 2: Schematic representation of functional assays based on DNA damage sensitivity. (A) Sensitivity to chemical or physical agents is determined by the spot assay. An overnight culture of yeast cells is serially diluted (10-fold dilution) and spotted onto plates containing the specific DNA damaging agent or are treated with UV. The effect of variants is determined by comparing growth of yeast expressing the variants vs WT. (B) The sensitivity to DNA damaging agents is evaluated by $\mathrm{OD}_{600}$ measurement of cell growth in liquid medium. Yeast cells are grown in medium containing the chemical agents or exposed to UV irradiation. The sensitivity of yeast cells carrying the gene variants is compared to yeast cells carrying the WT gene. MMS: methyl methane sulfonate; HU: hydroxyurea. 
say at the CAN1 locus (Figure $\mathbf{3 A}$ ) and reverse mutation assays at the hom3-10 (Figure $3 \mathrm{C}$ ) locus and lacZ (Figure 3D), the authors demonstrated that 13 out of $27 \mathrm{hMLH1}$ cancer-associated variants showed a functional impact. More recently, the dominant mutator effect has been evaluated for 101 hMLH1 cancer-associated variants by three yeast forward mutations assays (Figure 3D, 3E and 3F). The authors classified the variants in four categories depending on the results of the $L a c Z, G F P$, and $A D E 2$ assays. In this way, they could evaluate functionally subtle variants such as those responding only to one assay. A total of 70 variants gave loss of the mutator phenotype suggesting that this yeast assay could be a simple method to analyze a large number of variants [56].

Functional consequences of several cancer-associated $h M S H 2$ and $h M L H 1$ missense variants were also evaluated by mutating the corresponding yeast gene and determining the phenotype as compared to the WT strain. When a mu- tation has functional impact, it increases the spontaneous mutation rate conferring a mutator phenotype. In one study, twelve out of $17 M L H 1$ yeast variants corresponding to $h M L H 1$ cancer-associated mutations, showed a strong mutator phenotype assessed by forward mutation at the URA3 locus (Figure 3B) [53]. In another study, haploid yeast strains carrying six $M L H 1$ missense mutations that correspond to germline mutations found in human cancer patients, displayed a strong mutator phenotype when tested by forward (Figure 3A) and reverse mutation (Figure 3G and $3 \mathbf{H}$ ) [57]. A total of 28 alleles of yeast MLH1 corresponding to non-truncating human mutant alleles were studied in a reversion assay (Figure 3G); 24 alleles were able to induce a significant increase in the reversion rate [58]. Interestingly, yeast strains expressing the human mutated MLH1 alleles under control of the native yeast promoter, have been constructed in the MMR defective background (Figure 1C). The functional impact of eight $h M L H 1$

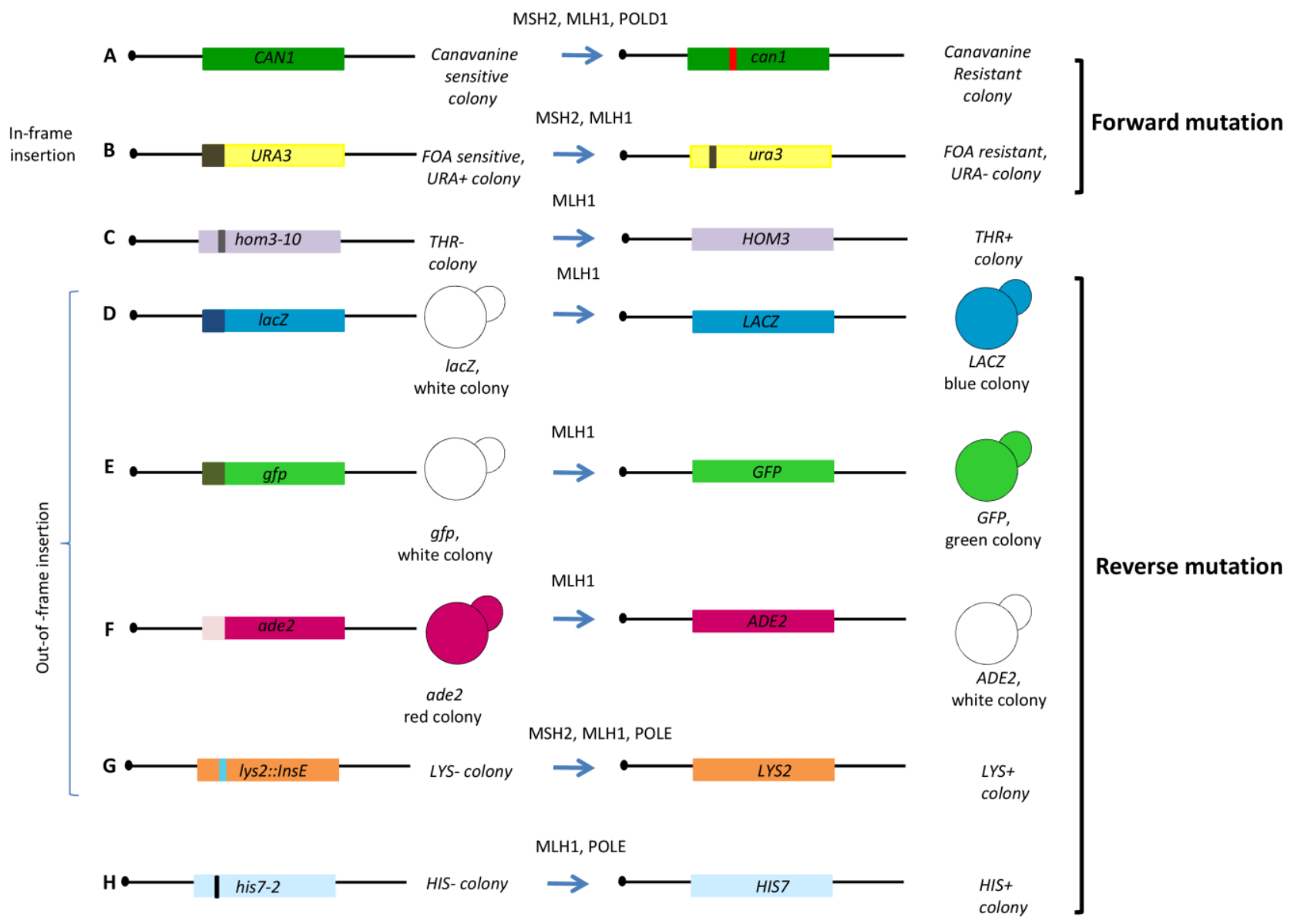

FIGURE 3: Schematic representation of the yeast functional assays for MMR genes. Forward mutation frequency/rate is evaluated by scoring the number of colonies becoming resistant to (A) Canavanine (CAN1 to can1) or (B) 5-fluoroorotic acid (5-FOA, URA3 to ura3). Reverse mutation is assessed by counting the number of colonies becoming able to grow in selective medium lacking threonine (C) (THR+; hom3-10 to HOM3), (D) colonies becoming blue (lacZ to LACZ), (E) colonies becoming green ( $g f p$ to GFP), (F) colonies becoming white in medium lacking adenine ( $A D E+$; ade2 to $A D E 2),(G)$ colonies becoming able to grow in medium lacking lysine (LYS+; lys2 to LYS2) and (H) colonies becoming able to grow in medium lacking histidine (HIS+, hys7-2 to HIS7). The URA3 gene used for forward reversion (B) contains an in-frame insertion of several nucleotides, therefore the gene is WT. Constructs of D, E, F and G contain out-of-frame insertion of several nucleotides, therefore the gene is mutated. Constructs of $\mathrm{C}$ and $\mathrm{H}$ contain a point mutation. Above the arrow are given the names of the human proteins studied with the assay. 
variants was determined by evaluating the effect on the mutation rate; three out of five pathogenic variants increased the mutation rate at the URA3 locus (Figure 3B) suggesting that complementation of yeast MMR defect by human corresponding alleles could be proposed as a system to characterize cancer-associated genetic variants [59]. Functional assays have also been performed for the MMR gene $M S H 2[52,53,60]$. As observed for $M L H 1$, yeast msh2 $\Delta$ shows a mutator phenotype that can be complemented by expressing $M S H 2$ WT from a plasmid. Exploiting the mutator phenotype of yeast $m s h 2 \Delta$, the effect of five yeast $\mathrm{MSH} 2$ missense mutations analogous to those found in $\mathrm{hMSH} 2$ were assayed by a reversion assay at the LYS2 locus (Figure 3G) [60]. In another assay, 54 missense mutations were introduced in the cognate positions in yeast MSH2 and tested for functional defects and assayed for their ability to induce forward mutations at the URA3 and CAN1 locus (Figure 3A and 3B). 34 cancer-associated variants conferred a mutator phenotype [52].

The assessment of the functional impact of cancerassociated DNA polymerase $\delta$ and $\varepsilon$ variants (POLD1 and $P O L E$ ) has been evaluated in yeast by constructing strains carrying the correspondent mutated amino acid identified by aligning yeast and human sequences. Since the yeast counterparts $P O L 3$ and $P O L 2$, respectively, are essential in yeast, functional assays have to be set up in diploid strains (with mutations in heterozygosis) or in haploid strains expressing WT POL genes from a plasmid (Figure 1D) [20,61]. The assays are based on the mutator effects of the cancerassociated Pol variants by comparing forward and reverse mutation rates observed in yeast strains carrying the variants with those observed in strains carrying the WT gene (Table1, Figure 3A, 3G and 3H). A total of 19 cancerassociated DNA polymerase variants were analyzed in yeast, 13 for Pole, and six for Pol $\delta[20,61]$. Cumulatively, these results showed that eight Pol $\varepsilon$ and 1 Pol $\delta$ variants confer a mutator phenotype. Moreover, one Pol $\delta$ variant

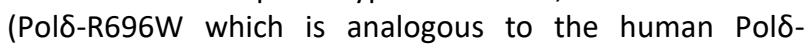
R689W variant) and one Pole (Pol2-R252H which is analogous to Pole-R231H) increased the mutation rate of the MMR defective yeast strain, suggesting a functional interplay between replication fidelity and $\operatorname{MMR}[20,61,62]$.

\section{Strategies to study DNA repair human genes lacking yeast orthologues}

Functional assays of human DNA repair genes lacking yeast orthologues have been performed for BRCA1 and BRCA2 (Table1). In order to develop assays for functional characterization of cancer- associated variants located in BRCA1 and $B R C A 2$, yeast strains overexpressing full length $B R C A 1$ or $B R C A 2$ under the control of a constitutive (pADH) or inducible promoter (pGAL1) have been constructed (Figure 1D) [63-67]. The BRCA1 gene encodes a nuclear phosphoprotein that plays a role in DNA damage repair, transcriptional regulation, cell cycle control and ubiquitylation. The BRCA1 protein exhibits several functions, including ubiquitin ligase activity, as well as nucleic acid binding activity and transcription coactivator activity. The protein consists of three main domains, the N-terminus -RING motif, the internal serine containing domain (SCD) and the BRCA1 Cterminus (BRCT) $[68,69]$. The BRCT domain of BRCA1 has been found to act as transactivation domain, therefore to study the impact of mutations of this domain, a transcription activation assay (TA) has been proposed (Figure $\mathbf{4 A}$ ) [70]. This assay is performed using a chimeric protein consisting of the C-terminus of BRCA1 (1396aa - 1863aa), which includes the BRCT domain, fused to the Gal4 or LexA DNA binding domain (DBD). This protein is able to activate transcription of the reporter gene LacZ integrated in the yeast genome or carried on an episomal plasmid, regulated by a minimal promoter containing Gal4 or LexA binding sites. Quantification of the reporter gene product permits an indirect assessment of the transcriptional activity mediated by the BRCA1 fusion protein and comparison between WT and variants allows to evaluate the impact of mutations [70, 71]. Carvalho et al. analyzed 24 variants located in the BRCT-BRCA1 domain and showed that the TA assay correctly classified all 24 variants [71]. More recently, Fernandes et al. classified 102 (99 missense and three truncating) variants located in the BRCA1-BRCT domain, by integrating data from a yeast-based TA assay with other functional data from a mammalian TA assay [72]. Overall, yeast the TA assay displayed $100 \%$ specificity and sensitivity [73] These results indicate that the yeast TA assay is accurate and can be very helpful to classify novel BRCA1 variants.

The expression of human BRCA1 WT in the budding yeast $S$. cerevisiae was found to strongly inhibit growth on solid medium (Figure 4B) [74]. This peculiar phenotype has been exploited to develop a simple functional assay named small colony phenotype assay (SCP) based on the ability conferred by BRCA1 pathogenic variants expression to restore yeast growth. The evaluation of the functional effects is determined by counting directly the number of cells per colony (Figure 4B) [63]. In total, 28 missense mutations were introduced in the BRCA1-BRCT domain; eleven mutations showed increased yeast colony size as compared to yeast expressing BRCA1 WT suggesting a disruption of $B R C T$ structure and/or function [63]. In addition, our group performed SCP assays to evaluate the functional impact of four mutations located in the BRCA1-BRCT domain; basically, we confirmed that this assay could be helpful to classify BRCT variants [65]. More recently, this assay has been validated by investigating the effect of as many as 40 (25 pathogenic and 15 neutral) variants located in almost all BRCA1 protein domains [75]. In this study, the specificity and sensitivity of the SCP assay was found to be $93 \%$ and $96 \%$ [75]. The same authors also validated the liquid medium assay that evaluates the growth inhibitory effect of BRCA1 in liquid medium over 15 hours (Figure 4C); however, this assay has less specificity and sensitivity than the SCP assay [75].

In the yeast localization phenotype (YLP) assay, the expression of BRCA1 WT fused to the mCherry red fluorescent protein provides qualitative information concerning the subcellular localization of BRCA1 since BRCA1-mCherry WT accumulates in a single inclusion body in the yeast nucleus while mutated BRCA1 pathogenic variants mainly 


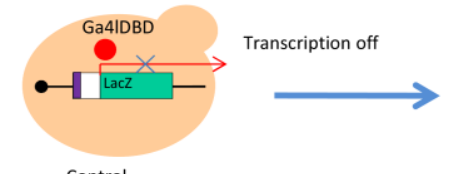

B Control

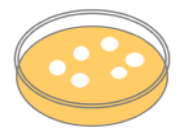

c

Contro

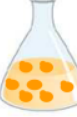

BRCA1-mCherry WT localizes as single aggregate inside the nucleus single agge日
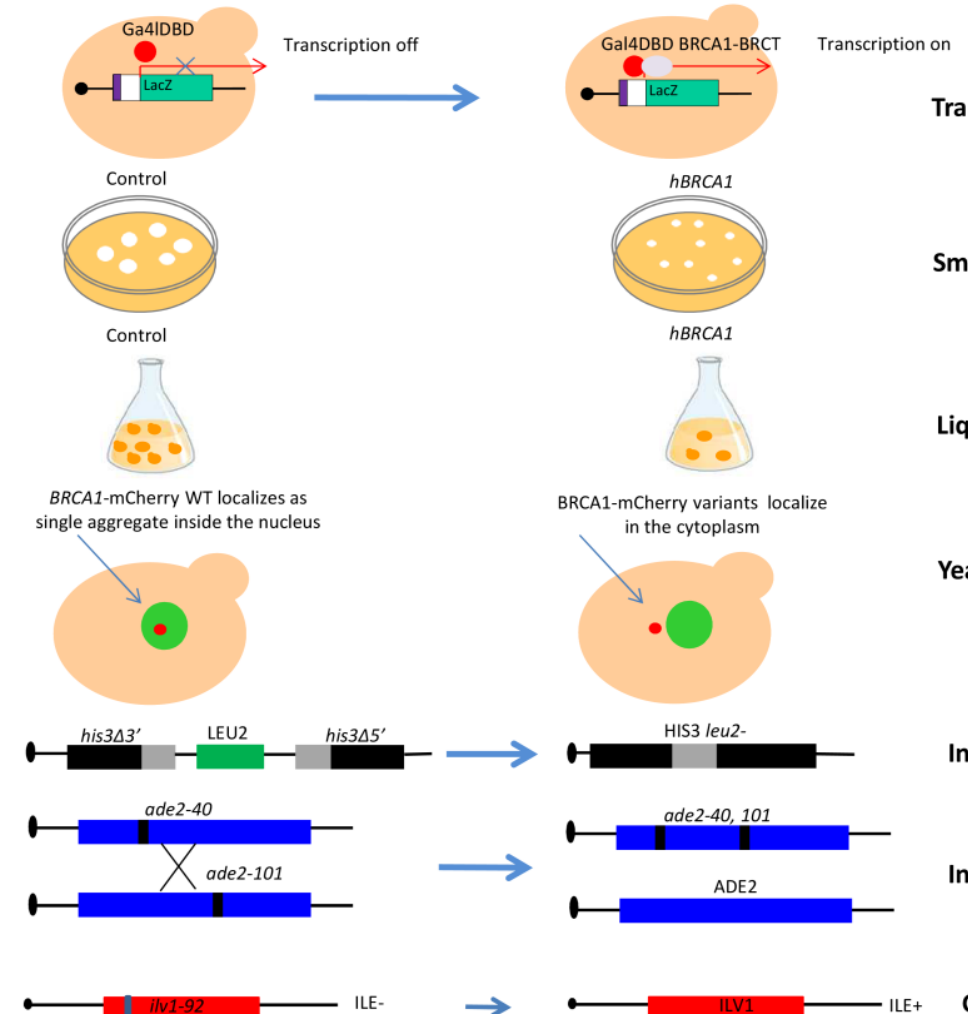

Transcription activation Assay (TA)

hBRCA1

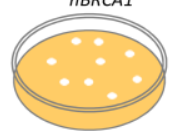

Small Colony Phenotype (SCP)

hBRCA

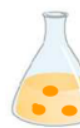

Liquid medium assay

BRCA1-mCherry variants localize

in the cytoplasm

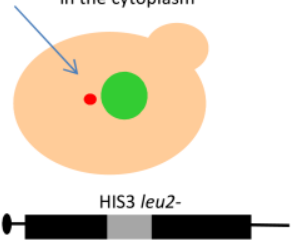

ade2-40, 101

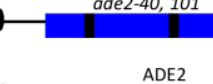

Yeast Localization Phenotype (YLP)

Intra-chromosomal Recombination

Inter-chromosomal Recombination

Gene Reversion (GR)

FIGURE 4: Schematic representation of the yeast functional assays for BRCA1/2 (A) Transcription activation assay (TA): The BRCT domain of BRCA1 is cloned in frame with the GAL4 or LexA DNA binding domain (DBD). WT BRCT fused to DBD is able to activate transcription of the reporter gene LacZ under control of the minimal promoter (white) containing the binding sequences (violet) recognized by the GAL4 or LexA DBD. Variants affecting BRCT domain activity are not able to activate LacZ transcription. (B) Small colony phenotype assay (SCP): yeast cells expressing BRCA1 (from pADH1 fused to the activation domain of GAL4, or from inducible pGAL1) form colonies considerably smaller than controls after incubation at $30^{\circ} \mathrm{C}$. Yeast colonies re resuspended in water, and the number of cells per colony are determined by counting. Small colonies correlate with slow growth, therefore the inhibition of growth determined by BRCA1 expression can be performed also in liquid medium. (C) Liquid Medium assay: this assay monitors the growth defect of yeast cells expressing BRCA1 as in the SCP, but in liquid instead of solid medium. (D) Yeast localization phenotype assay (YLP) this assay is performed in yeast cells expressing BRCA1 cloned in frame with $\mathrm{m}$-Cherry at C-terminus (BRCA1-mCherry) under control of the inducible GAL promoter. Yeast cells expressing WT or BRCA1 variants fused to mCherry are induced for $4 \mathrm{~h}$ with galactose before live fluorescent microscopy analyses. The nucleus is identified by the expression of the nuclear protein Nup133 fused to GFP (Nup133-GFP, green). Whereas the WT BRCA1 protein shows mainly nuclear localization (Red spot), pathogenic variants show prevalent cytoplasmic localization. (E) Intra- chromosomal recombination: the yeast strain carries the two his 3 alleles separated by the LEU2 marker and by the plasmid DNA sequence, one with a deletion at the $3^{\prime}$ end and the other with a deletion at the $5^{\prime}$ end, which share 400 bp of homology (gray box). An intra-chromosomal recombination event leads to HIS3 reversion and loss of LEU2 determined by counting colonies grown in medium lacking histidine (HIS3+). (F) Inter-chromosomal recombination: the yeast strain contains the two alleles ade2-40 and ade2-101, located in two homologous chromosomes. An inter-chromosomal recombination event leads to WT $A D E 2$ determined directly by counting colonies grown in medium lacking adenine (ADE2+). (G) Gene reversion (GR): the yeast strain carries the ilv1-92 that allows the assessment of gene reversion to ILV1 by direct counting colonies grown in medium lacking isoleucine (ILE+).

localize in the cytoplasm (Figure 4D) [64]. This assay was validated by studying a total of 40 variants ( 25 pathogenic and 15 neutral) previously analyzed with the SCP assay; results indicated that the YLP assay has less sensitivity $(84 \%)$ and the same specificity $(93 \%)$ as SCP $[73,75]$.

Other assays to evaluate the impact of missense mutations in BRCA1 have been developed by our group. Since $B R C A 1$ is involved in DNA repair, we developed two HR assays to evaluate the impact of variants on intra- and inter-chromosomal recombination (Figure $\mathbf{4 E}$ and $\mathbf{4 F}$ ), and one assay to assess their effect on gene reversion (GR) at the ilv1-92 locus (Figure 4G) [65, 76, 77]. In our first explorative paper, we demonstrated the validity of the assay analyzing the effect of twelve BRCA1 variants (four pathogenic, seven neutral and one not classified) in a diploid yeast strain carrying the two different HR substrates to measure intra-chromosomal and inter-chromosomal recombination events [65]. Results demonstrated that the four pathogenic variants significantly induced at least one HR event. The effect of BRCA1 pathogenic variants on GR was also evaluated in a haploid yeast strain. Results indicated that four out of five pathogenic variants and to out of six neutral variants induced a significant GR increase confirming the yeast system as a valuable tool to classify uncharacterized $B R C A 1$ variants [76, 77]. 
Intra-chromosomal and inter-chromosomal HR assays have also been used to evaluate the effect of missense variants of BRCA2. The expression of BRCA2 WT in yeast increases both intra-chromosomal and inter-chromosomal HR [66]. Spugnesi et al. observed that one pathogenic variant did not affect $H R$, while the neutral variants significantly increased HR to the level of BRCA2 WT [66]. To understand the potential application of this assay in clinical genetics, a larger number of classified variants needs to be studied.

\section{CONCLUSIONS AND PERSPECTIVES}

Overall, the advantage of functional assays is to provide results that can be applied to clinical genetics in order to classify novel variants. For this purpose, functional assays need to be statistically validated using a significant number (at least 40) of classified variants (pathogenic and benign) and the WT protein as control [75]. Cancer-associated variants of BRCA1 and the MMR genes MSH2, MLH1 are the most studied in yeast and several functional assays have been developed in order to classify VUS. Functional assays to assess the impact of mutations of MMR genes are based on the evaluation of the effect of mutations on the mutator phenotype i.e. the pathogenic variants should affect mutation rate as compared to the WT. The International Society for Gastrointestinal Hereditary Tumours (InSiGHT, https://www.insight-group.org/) established criteria and guidelines for the classification of new MMR variants, and provided a list of MMR functional assays that could be helpful to classify new variants [78]. InSiGHT also indicates that yeast-based MMR functional assays should not be considered definitive for variant classification, but only to assess pathogenicity. This assumption is based on the detailed examination of results of yeast assays for variants considered benign: discordant results were reported for $8 / 19$ (42\%) variants assayed, as compared to only $1 / 18$ (5.5\%) in mammalian assays [78]. However, this conclusion is drawn from a very limited number of variants and requires a larger data set for a more accurate analysis. In addition, the difficulties experienced in interpreting apparently discordant data from functional assays emphasize the importance of assay validation and standardization.

A range of different assays have been used to assess the effects of BRCA1 variants on protein function, some limited to measure the functional impact of variants within a specific domain (TA assay and SCP), and others to measure output relevant to variants located anywhere in the coding region (HR and GR assay) $[38,77]$. The consortium ENIGMA (Evidence-based Network for the Interpretation of Germline Mutant Alleles, http://enigmaconsortium.org/) has developed $B R C A 1 / 2$ variant classification criteria that utilize statistical and qualitative methods including functional data to assess the clinical significance of variants. Particularly, ENIGMA provides guidance and rules on how to integrate $B R C A 1 / 2$ protein functional data for classification of $B R C A 1 / 2$ missense variants. To evaluate the strength of these assays as predictors of the clinical significance of newly identified VUS, sensitivity and specificity of assays should be determined using previously classified missense variants. For multi-domain proteins such as BRCA1, some assays need an integrative statistical validation by analyzing large numbers of variants and by comparing data from them with data from other analysis [79]. Yeast-based SCP, YLP and TA assays have been recently validated and therefore could be useful for classifying VUS according to ENIGMA rules [75] [72].

Functional assays have traditionally been applied to each newly identified VUS, but the rapid increase of VUS has prompted the proposal of novel strategies to determine clinical significance of thousands of variants simultaneously [80]. The approach named multiplexed assay of variant effect (MAVE) could really contribute to evaluate functional consequences of human genetic variation [81] MAVE has allowed the assessment of thousand variants located in coding sequence, enhancers and promoters [82]. Importantly, MAVE analysis have been carried out in several genetic systems including yeast [83, 84]. In general, MAVE is based on the construction of a library of variants to be introduced in the cells, and on the evaluation of GFPbased recombination systems or growth assays [85]. Therefore, selection and read-out methods to assess the functional impact of variants are crucial for VUS classification. Recently, Findaly et al. analyzed the functional consequences of almost 4,000 BRCA1 variants located in 13 exons by using a CRISP-Cas9 saturation mutagenesis approach. Functional scores (FS) are determined by measuring the effect of the BRCA1 variants on growth in a haploid cell line [86]; moreover, FS are highly accurate to predict pathogenicity with sensitivity and specificity over $95 \%$. Very recently, a novel high-throughput method for functional analysis was developed to assess the pathogenicity of VUS within BRCA2; out of 244 total variants, as many as 186 pathogenic variants were identified. Sensitivity and specificity of this assay were estimated to be $95 \%$ [87].

MAVE strategy has been applied to several clinically relevant proteins including the tumor suppressor TP53 and PTEN producing a large amount of data that could be potentially useful for clinical applications. Recently, detailed recommendations on how to perform MAVE data collection and interpretation, and even to design a MAVE screening, have been published [82]. Indeed, these new methods may provide FS that can be used to classify the variants; however, some of them do not rely on the biological function of the protein and a direct comparison to WT is lacking. Therefore, to investigate functional consequences of cancer-associated variants in validated yeast-based assays that rely on the biological function of the protein would be preferable, because data are easier to interpret and compare to other functional assays. Moreover, for a more complete evaluation of the functional impact of many variants, comparative studies using several assays are preferable, particularly for "intermediate" or "low risk" variants. In the next future, it would be very helpful to apply MAVE in yeast for functional evaluation of variants located in DNA repair genes such as Rad51/52 or MMR genes; the challenge is to develop reporter systems that score for mutator or HR effects. 


\section{ACKNOWLEDGMENTS}

The authors wish to thank all the members of the laboratory for suggestions and comments. Special thanks to Marcella Simili and Michael Minks for critical reading and language editing. The work in the lab is supported by the grant $127 / 16$ funded by the "Fondazione Pisa" assigned to AG.

\section{CONFLICT OF INTEREST}

The authors declare that there are no conflicts of interest.

\section{REFERENCES}

1. Negrini S, Gorgoulis VG, Halazonetis TD (2010). Genomic instability-an evolving hallmark of cancer. Nat Rev Mol Cell Biol 11(3): 220-228. doi: $10.1038 / \mathrm{nrm} 2858$

2. Taylor EM, Lehmann AR (1998). Conservation of eukaryotic DNA repair mechanisms. Int J Radiat Biol 74(3): 277-286. doi 10.1080/095530098141429.

3. Das R, Ghosh SK (2017). Genetic variants of the DNA repair genes from Exome Aggregation Consortium (EXAC) database: significance in cancer. DNA Repair 52: 92-102. doi:10.1016/j.dnarep.2017.02.013

4. Chatterjee N, Walker GC (2017). Mechanisms of DNA damage, repair, and mutagenesis. Environ Mol Mutagen 58(5): 235-263. doi 10.1002/em.22087

5. Lee KY, Myung K (2008). PCNA modifications for regulation of postreplication repair pathways. Mol Cells 26(1): 5-11. PMID: 18525240

6. Wang Q (2016). Cancer predisposition genes: molecular mechanisms and clinical impact on personalized cancer care: examples of Lynch and HBOC syndromes. Acta Pharmacol Sin 37(2): 143-149. doi: 10.1038/aps.2015.89

7. Nielsen FC, van Overeem Hansen T, Sorensen CS (2016). Hereditary breast and ovarian cancer: new genes in confined pathways. Nat Rev Cancer 16(9): 599-612. doi: 10.1038/nrc.2016.72

8. Slavin TP, Maxwell KN, Lilyquist J, Vijai J, Neuhausen SL, Hart SN Ravichandran V, Thomas T, Maria A, Villano D, Schrader KA, Moore R, Hu C, Wubbenhorst B, Wenz BM, D'Andrea K, Robson ME, Peterlongo $P$, Bonanni B, Ford JM, Garber JE, Domchek SM, Szabo C, Offit K, Nathanson KL, Weitzel JN, Couch FJ (2017). The contribution of pathogenic variants in breast cancer susceptibility genes to familial breast cancer risk. NPJ Breast Cancer 3: 22. doi: 10.1038/s41523-017 0024-8

9. Jia J, Ren J, Yan D, Xiao L, Sun R (2015). Association between the XRCC6 polymorphisms and cancer risks: a systematic review and meta-analysis. Medicine 94(1): e283. doi: 10.1097/MD.0000000000000283

10. Goode EL, Ulrich CM, Potter JD (2002). Polymorphisms in DNA repair genes and associations with cancer risk. Cancer Epidemiol Biomarkers Prev 11(12): 1513-1530. PMID: 12496039

11. Sung P, Prakash L, Matson SW, Prakash S (1987). RAD3 protein of Saccharomyces cerevisiae is a DNA helicase. Proc Natl Acad Sci U S A 84(24): 8951-8955. doi: 10.1073/pnas.84.24.8951

12. Weber CA, Salazar EP, Stewart SA, Thompson LH (1990). ERCC2 cDNA cloning and molecular characterization of a human nucleotide excision repair gene with high homology to yeast RAD3. EMBO J 9(5): 1437-1447. doi: 10.1002/j.1460-2075.1990.tb08260.x

\section{COPYRIGHT}

(C) 2020 Cervelli et al. This is an open-access article released under the terms of the Creative Commons Attribution (CC BY) license, which allows the unrestricted use, distribution, and reproduction in any medium, provided the original author and source are acknowledged.

Please cite this article as: Tiziana Cervelli, Samuele Lodovichi, Francesca Bellè and Alvaro Galli (2020). Yeast-based assays for the functional characterization of cancer-associated variants of human DNA repair genes. Microbial Cell 7(7): 162-174. doi: 10.15698/mic2020.07.721

13. Manuguerra $M$, Saletta $F$, Karagas $M R$, Berwick $M$, Veglia $F$, Vineis $P$, Matullo $G$ (2006). XRCC3 and XPD/ERCC2 single nucleotide polymorphisms and the risk of cancer: a HuGE review. Am J Epidemiol 164(4): 297-302. doi:10.1093/aje/kwj189

14. Phelan A, Lopez-Beltran A, Montironi R, Zhang S, Raspollini MR, Cheng $M$, Kaimakliotis $\mathrm{HZ}$, Koch MO, Cheng L (2018). Inherited forms of bladder cancer: a review of Lynch syndrome and other inherited conditions. Future Oncol 14(3): 277-290. doi: 10.2217/fon-2017-0346

15. Nguyen-Dumont T, Steen JA, Winship I, Park DJ, Pope BJ, Hammet F, Mahmoodi M, Tsimiklis $H$, Theys $D$, Clendenning M, Giles GG, Hopper JL, Southey MC (2020). Mismatch repair gene pathogenic germline variants in a population-based cohort of breast cancer. Fam Cancer. doi: 10.1007/s10689-020-00164-7

16. Simonelli V, Leuzzi G, Basile G, D'Errico M, Fortini P, Franchitto A Viti V, Brown AR, Parlanti E, Pascucci B, Palli D, Giuliani A, Palombo F, Sobol RW, Dogliotti E (2017). Crosstalk between mismatch repair and base excision repair in human gastric cancer. Oncotarget 8(49): 84827-84840. doi: 10.18632/oncotarget.10185

17. Tedaldi G, Tebaldi M, Zampiga V, Danesi R, Arcangeli V, Ravegnan M, Cangini I, Pirini F, Petracci E, Rocca A, Falcini F, Amadori D, Calistr $D$ (2017). Multiple-gene panel analysis in a case series of 255 women with hereditary breast and ovarian cancer. Oncotarget 8(29): 4706447075. doi: 10.18632/oncotarget.16791

18. Barbari SR, Shcherbakova PV (2017). Replicative DNA polymerase defects in human cancers: Consequences, mechanisms, and implications for therapy. DNA Repair 56(16-25. doi: 10.1016/j.dnarep.2017.06.003

19. Rayner E, van Gool IC, Palles C, Kearsey SE, Bosse T, Tomlinson I, Church DN (2016). A panoply of errors: polymerase proofreading domain mutations in cancer. Nat Rev Cancer 16(2): 71-81. doi: $10.1038 /$ nrc. 2015.12

20. Barbari SR, Kane DP, Moore EA, Shcherbakova PV (2018). Functional Analysis of Cancer-Associated DNA Polymerase epsilon Variants in Saccharomyces cerevisiae. G3 8(3): 1019-1029. doi: 10.1534/g3.118.200042

21. Srivastava M, Raghavan SC (2015). DNA double-strand break repair inhibitors as cancer therapeutics. Chem Biol 22(1): 17-29. doi: 10.1016/j.chembiol.2014.11.013

22. Huang J, Huen MS, Kim H, Leung CC, Glover JN, Yu X, Chen J (2009). RAD18 transmits DNA damage signalling to elicit homologous recombination repair. Nat Cell Biol 11(5): 592-603. doi: $10.1038 /$ ncb1865 
23. Ting L, Jun $H$, Junjie $C$ (2010). RAD18 lives a double life: Its implication in DNA double-strand break repair. DNA Repair 9(12) 1241-1248. doi: 10.1016/j.dnarep.2010.09.016

24. de Padula M, Slezak G, Auffret van Der Kemp P, Boiteux S (2004). The post-replication repair RAD18 and RAD6 genes are involved in the prevention of spontaneous mutations caused by 7,8-dihydro-8 oxoguanine in Saccharomyces cerevisiae. Nucleic Acids Res 32(17): 5003-5010. doi: 10.1093/nar/gkh831

25. Wong RP, Aguissa-Toure AH, Wani AA, Khosravi S, Martinka M, Li $G$ (2012). Elevated expression of Rad18 regulates melanoma cell proliferation. Pigment Cell Melanoma Res 25(2): 213-218. doi: 10.1111/j.1755-148X.2011.00948.x

26. Sasatani M, Xu Y, Kawai H, Cao L, Tateishi S, Shimura T, Li J, lizuka D, Noda A, Hamasaki K, Kusunoki Y, Kamiya K (2015). RAD18 activates the $G 2 / M$ checkpoint through DNA damage signaling to maintain genome integrity after ionizing radiation exposure. PLoS One 10(2): e0117845. doi: 10.1371/journal.pone.0117845

27. Yan X, Chen J, Meng Y, He C, Zou S, Li P, Chen M, Wu J, Ding WQ, Zhou J (2019). RAD18 may function as a predictor of response to preoperative concurrent chemoradiotherapy in patients with locally advanced rectal cancer through caspase-9-caspase-3-dependent apoptotic pathway. Cancer Med 8(6): 3094-3104. doi: 10.1002/cam4.2203

28. Visnes T, Grube M, Hanna BMF, Benitez-Buelga C, Cazares-Korner A, Helleday $T$ (2018). Targeting BER enzymes in cancer therapy. DNA Repair 71: 118-126. doi: 10.1016/j.dnarep.2018.08.015

29. Trenner A, Sartori AA (2019). Harnessing DNA Double-Strand Break Repair for Cancer Treatment. Front Oncol 9(1388. doi: 10.3389/fonc. 2019.01388

30. Curtin NJ (2012). DNA repair dysregulation from cancer driver to therapeutic target. Nat Rev Cancer 12(12): 801-817. doi: $10.1038 /$ nrc3399

31. Feng Z, Scott SP, Bussen W, Sharma GG, Guo G, Pandita TK, Powell SN (2011). Rad52 inactivation is synthetically lethal with BRCA2 deficiency. Proc Natl Acad Sci U S A 108(2): 686-691. doi: 10.1073/pnas.1010959107

32. Jalan M, Olsen KS, Powell SN (2019). Emerging Roles of RAD52 in Genome Maintenance. Cancers 11(7): E1038. doi: 10.3390/cancers11071038

33. Lappalainen T, Scott AJ, Brandt M, Hall IM (2019). Genomic Analysis in the Age of Human Genome Sequencing. Cell 177(1): 70-84 doi: 10.1016/j.cell.2019.02.032

34. Richards S, Aziz N, Bale S, Bick D, Das S, Gastier-Foster J, Grody WW, Hegde M, Lyon E, Spector E, Voelkerding K, Rehm HL (2015). Standards and guidelines for the interpretation of sequence variants: a joint consensus recommendation of the American College of Medical Genetics and Genomics and the Association for Molecular Pathology. Genet Med 17(5): 405-424. doi: 10.1038/gim.2015.30

35. Pollard S, Sun S, Regier DA (2019). Balancing uncertainty with patient autonomy in precision medicine. Nat Rev Genet 20(5): 251252. doi: 10.1038/s41576-019-0111-9

36. Tsaousis GN, Papadopoulou E, Apessos A, Agiannitopoulos K, Pepe G, Kampouri S, Diamantopoulos N, Floros T, losifidou R, Katopodi O, Koumarianou A, Markopoulos C, Papazisis K, Venizelos V, Xanthakis I, Xepapadakis G, Banu E, Eniu DT, Negru S, Stanculeanu DL, Ungureanu A, Ozmen V, Tansan S, Tekinel M, Yalcin S, Nasioulas G (2019). Analysis of hereditary cancer syndromes by using a panel of genes: novel and multiple pathogenic mutations. BMC Cancer 19(1): 535 . doi: 10.1186/s12885-019-5756-4

37. Couch FJ, Rasmussen LJ, Hofstra R, Monteiro AN, Greenblatt MS, de Wind $N$ (2008). Assessment of functional effects of unclassified genetic variants. Hum Mutat 29(11): 1314-1326. doi: 10.1002/humu.20899

38. Millot GA, Carvalho MA, Caputo SM, Vreeswijk MP, Brown MA Webb M, Rouleau E, Neuhausen SL, Hansen T, Galli A, Brandao RD, Blok MJ, Velkova A, Couch FJ, Monteiro AN (2012). A guide for functional analysis of BRCA1 variants of uncertain significance. Hum Mutat 33(11): 1526-1537. doi: 10.1002/humu.22150

39. Abugable AA, Awwad DA, Fleifel D, Ali MM, El-Khamisy S, Elserafy $M$ (2017). Personalised Medicine: Genome Maintenance Lessons Learned from Studies in Yeast as a Model Organism. Adv Exp Med Biol 1007: 157-178. doi: 10.1007/978-3-319-60733-7_9

40. Ou J, Niessen RC, Lutzen A, Sijmons RH, Kleibeuker JH, de Wind N, Rasmussen $\sqcup$, Hofstra RM (2007). Functional analysis helps to clarify the clinical importance of unclassified variants in DNA mismatch repair genes. Hum Mutat 28(11): 1047-1054. doi: 10.1002/humu.20580

41. Andersen SD, Liberti SE, Lutzen A, Drost $M$, Bernstein I, Nilbert $M$, Dominguez M, Nystrom M, Hansen TV, Christoffersen JW, Jager AC, de Wind N, Nielsen FC, Torring PM, Rasmussen $\amalg$ (2012). Functional characterization of MLH1 missense variants identified in Lynch syndrome patients. Hum Mutat 33(12): 1647-1655. doi: 10.1002/humu.22153

42. Guidugli L, Carreira A, Caputo SM, Ehlen A, Galli A, Monteiro AN Neuhausen SL, Hansen TV, Couch FJ, Vreeswijk MP (2014). Functional assays for analysis of variants of uncertain significance in BRCA2. Hum Mutat 35(2): 151-164. doi: 10.1002/humu.22478

43. Douzery EJ, Snell EA, Bapteste E, Delsuc F, Philippe H (2004). The timing of eukaryotic evolution: does a relaxed molecular clock reconcile proteins and fossils? Proc Natl Acad Sci U S A 101(43): 15386-15391. doi: 10.1073/pnas.0403984101

44. Kachroo AH, Laurent JM, Yellman CM, Meyer AG, Wilke CO Marcotte EM (2015). Evolution. Systematic humanization of yeast genes reveals conserved functions and genetic modularity. Science 348(6237): 921-925. doi: 10.1126/science.aaa0769

45. Hamza A, Tammpere E, Kofoed M, Keong C, Chiang J, Giaever G, Nislow C, Hieter P (2015). Complementation of Yeast Genes with Human Genes as an Experimental Platform for Functional Testing of Human Genetic Variants. Genetics 201(3): 1263-1274. doi: 10.1534/genetics.115.181099

46. Laurent JM, Young JH, Kachroo AH, Marcotte EM (2015). Efforts to make and apply humanized yeast. Brief Funct Genomics 15(2):155-63. doi: 10.1093/bfgp/elv041

47. Aggarwal M, Brosh RM, Jr. (2012). Functional analyses of human DNA repair proteins important for aging and genomic stability using yeast genetics. DNA Repair 11(4): 335-348. doi: 10.1016/j.dnarep.2012.01.013

48. Mercatanti A, Lodovichi S, Cervelli T, Galli A (2017). CRIMEtoYHU: a new web tool to develop yeast-based functional assays for characterizing cancer-associated missense variants. FEMS Yeast Res 17(8). doi: 10.1093/femsyr/fox078

49. Lee MS, Yu M, Kim KY, Park GH, Kwack K, Kim KP (2015). Functional Validation of Rare Human Genetic Variants Involved in Homologous Recombination Using Saccharomyces cerevisiae. PLoS One 10(5): e0124152. doi: 10.1371/journal.pone.0124152

50. Kim C, Yang J, Jeong SH, Kim H, Park GH, Shin HB, Ro M, Kim KY Park Y, Kim KP, Kwack K (2018). Yeast-based assays for characterization of the functional effects of single nucleotide polymorphisms in human DNA repair genes. PLoS One 13(3): e0193823. doi: 10.1371/journal.pone.0193823

51. Shimodaira $H$, Filosi N, Shibata $H$, Suzuki T, Radice $P$, Kanamaru $R$, Friend SH, Kolodner RD, Ishioka C (1998). Functional analysis of 
human MLH1 mutations in Saccharomyces cerevisiae. Nat Genet 19(4): 384-389. doi: 10.1038/1277

52. Gammie AE, Erdeniz N, Beaver J, Devlin B, Nanji A, Rose MD (2007) Functional characterization of pathogenic human $\mathrm{MSH} 2$ missense mutations in Saccharomyces cerevisiae. Genetics 177(2): 707-721. doi: 10.1534/genetics.107.071084

53. Ellison AR, Lofing J, Bitter GA (2001). Functional analysis of human MLH1 and MSH2 missense variants and hybrid human-yeast MLH1 proteins in Saccharomyces cerevisiae. Hum Mol Genet 10(18): 18891900. doi: $10.1093 / \mathrm{hmg} / 10.18 .1889$

54. Rasmussen LJ, Heinen CD, Royer-Pokora B, Drost M, Tavtigian S, Hofstra RM, de Wind N (2012). Pathological assessment of mismatch repair gene variants in Lynch syndrome: past, present, and future. Hum Mutat 33(12): 1617-1625. doi: 10.1002/humu.22168

55. Aldred PM, Borts RH (2007). Humanizing mismatch repair in yeast: towards effective identification of hereditary non-polyposis colorectal cancer alleles. Biochem Soc Trans 35(Pt 6): 1525-1528. doi:10.1042/BST0351525

56. Takahashi M, Shimodaira H, Andreutti-Zaugg C, Iggo R, Kolodner RD, Ishioka C (2007). Functional analysis of human MLH1 variants using yeast and in vitro mismatch repair assays. Cancer Res 67(10): 4595-4604. doi: 10.1158/0008-5472.CAN-06-3509

57. Shcherbakova PV, Kunkel TA (1999). Mutator phenotypes conferred by MLH1 overexpression and by heterozygosity for mlh1 mutations. Mol Cell Biol 19(4): 3177-3183. doi: 10.1128/mcb.19.4.3177

58. Wanat JJ, Singh N, Alani E (2007). The effect of genetic background on the function of Saccharomyces cerevisiae mlh1 alleles that correspond to HNPCC missense mutations. Hum Mol Genet 16(4): 445-452. doi: 10.1093/hmg/ddl479

59. Vogelsang M, Comino A, Zupanec N, Hudler P, Komel R (2009). Assessing pathogenicity of MLH1 variants by co-expression of human MLH1 and PMS2 genes in yeast. BMC Cancer 9: 382. doi: 10.1186/1471-2407-9-382

60. Drotschmann K, Clark AB, Tran HT, Resnick MA, Gordenin DA, Kunkel TA (1999). Mutator phenotypes of yeast strains heterozygous for mutations in the MSH2 gene. Proc Natl Acad Sci U S A 96(6): 29702975. doi: 10.1073/pnas.96.6.2970

61. Daee DL, Mertz TM, Shcherbakova PV (2010). A cancer-associated DNA polymerase delta variant modeled in yeast causes a catastrophic increase in genomic instability. Proc Natl Acad Sci U S A 107(1): 157162. doi: 10.1073/pnas.0907526106

62. Mertz TM, Sharma S, Chabes A, Shcherbakova PV (2015). Colon cancer-associated mutator DNA polymerase delta variant causes expansion of dNTP pools increasing its own infidelity. Proc Natl Acad Sci U S A 112(19): E2467-2476. doi: 10.1073/pnas.1422934112

63. Coyne RS, McDonald HB, Edgemon K, Brody LC (2004). Functional characterization of BRCA1 sequence variants using a yeast small colony phenotype assay. Cancer Biol Ther 3(5): 453-457. doi: 10.4161/cbt.3.5.809

64. Millot GA, Berger A, Lejour V, Boule JB, Bobo C, Cullin C, Lopes J, Stoppa-Lyonnet D, Nicolas A (2011). Assessment of human Nter and Cter BRCA1 mutations using growth and localization assays in yeast. Hum Mutat 32(12): 1470-1480. doi: 10.1002/humu.21608

65. Caligo MA, Bonatti F, Guidugli L, Aretini P, Galli A (2009). A yeast recombination assay to characterize human BRCA1 missense variants of unknown pathological significance. Hum Mutat 30(1): 123-133. doi: 10.1002/humu.20817

66. Spugnesi L, Balia C, Collavoli A, Falaschi E, Quercioli V, Caligo MA, Galli A (2013). Effect of the expression of BRCA2 on spontaneous homologous recombination and DNA damage-induced nuclear foci in Saccharomyces cerevisiae. Mutagenesis 28(2): 187-195. doi: 10.1093/mutage/ges069

67. Monteiro AN, August A, Hanafusa H (1996). Evidence for a transcriptional activation function of BRCA1 C-terminal region. Proc Natl Acad Sci U S A 93(24): 13595-13599. doi: 10.1073/pnas.93.24.13595

68. Narod SA, Foulkes WD (2004). BRCA1 and BRCA2: 1994 and beyond. Nat Rev Cancer 4(9): 665-676. doi: 10.1038/nrc1431

69. Clark SL, Rodriguez AM, Snyder RR, Hankins GD, Boehning D (2012). Structure-Function Of The Tumor Suppressor BRCA1. Comput Struct Biotechnol J 1(1): e201204005. doi: 10.5936/csbj.201204005

70. Hayes F, Cayanan C, Barilla D, Monteiro AN (2000). Functional assay for BRCA1: mutagenesis of the $\mathrm{COOH}$-terminal region reveals critical residues for transcription activation. Cancer Res 60(9): 24112418. PMID: 10811118

71. Carvalho MA, Marsillac SM, Karchin R, Manoukian S, Grist S, Swaby RF, Urmenyi TP, Rondinelli E, Silva R, Gayol L, Baumbach L, Sutphen R, Pickard-Brzosowicz JL, Nathanson KL, Sali A, Goldgar D, Couch FJ, Radice $P$, Monteiro AN (2007). Determination of cancer risk associated with germ line BRCA1 missense variants by functional analysis. Cancer Res 67(4): 1494-1501. doi: 10.1158/0008-5472.CAN-06-3297

72. Fernandes VC, Golubeva VA, Di Pietro G, Shields C, Amankwah K, Nepomuceno TC, de Gregoriis G, Abreu RBV, Harro C, Gomes TT, Silva RF, Suarez-Kurtz G, Couch FJ, Iversen ES, Monteiro ANA, Carvalho MA (2019). Impact of amino acid substitutions at secondary structures in the BRCT domains of the tumor suppressor BRCA1: Implications for clinical annotation. J Biol Chem 294(15): 5980-5992. doi: 10.1074/jbc.RA118.005274

73. Monteiro AN, Bouwman P, Kousholt AN, Eccles DM, Millot GA, Masson JY, Schmidt MK, Sharan SK, Scully R, Wiesmuller L, Couch F, Vreeswijk MPG (2020). Variants of uncertain clinical significance in hereditary breast and ovarian cancer genes: best practices in functional analysis for clinical annotation. J Med Genet. doi: 10.1136/jmedgenet-2019-106368

74. Humphrey JS, Salim A, Erdos MR, Collins FS, Brody LC, Klausner RD (1997). Human BRCA1 inhibits growth in yeast: potential use in diagnostic testing. Proc Natl Acad Sci U S A 94(11): 5820-5825. doi: 10.1073/pnas.94.11.5820

75. Thouvenot $P$, Ben Yamin $B$, Fourriere $L$, Lescure $A$, Boudier $T$, Del Nery E, Chauchereau A, Goldgar DE, Houdayer C, Stoppa-Lyonnet D, Nicolas A, Millot GA (2016). Functional Assessment of Genetic Variants with Outcomes Adapted to Clinical Decision-Making. PLoS Genet 12(6): e1006096. doi: 10.1371/journal.pgen.1006096

76. Maresca L, Lodovichi S, Lorenzoni A, Cervelli T, Monaco R, Spugnesi L, Tancredi M, Falaschi E, Zavaglia K, Landucci E, Roncella M, Congregati C, Gadducci A, Naccarato AG, Caligo MA, Galli A (2018). Functional Interaction Between BRCA1 and DNA Repair in Yeast May Uncover a Role of RAD50, RAD51, MRE11A, and MSH6 Somatic Variants in Cancer Development. Front Genet 9: 397. doi: 10.3389/fgene. 2018.00397

77. Lodovichi S, Belle F, Cervelli T, Lorenzoni A, Maresca L, Cozzani C, Caligo MA, Galli A (2020). Effect of BRCA1 missense variants on gene reversion in DNA double-strand break repair mutants and cell cyclearrested cells of Saccharomyces cerevisiae. Mutagenesis 35(2): 189195. doi: 10.1093/mutage/gez043

78. Thompson BA, Spurdle AB, Plazzer JP, Greenblatt MS, Akagi K, AlMulla F, Bapat B, Bernstein I, Capella G, den Dunnen JT, du Sart D, Fabre A, Farrell MP, Farrington SM, Frayling IM, Frebourg T, Goldgar $D E$, Heinen $C D$, Holinski-Feder $E$, Kohonen-Corish $M$, Robinson $K L$, Leung SY, Martins A, Moller P, Morak M, Nystrom M, Peltomaki $P$, Pineda M, Qi M, Ramesar R, et al. (2014). Application of a 5-tiered 
scheme for standardized classification of 2,360 unique mismatch repair gene variants in the InSiGHT locus-specific database. Nat Genet 46(2): 107-115. doi: 10.1038/ng.2854

79. Parsons MT, Tudini E, Li H, Hahnen E, Wappenschmidt B, Feliubadalo L, Aalfs CM, Agata S, Aittomaki K, Alducci E, Alonso-Cerezo MC, Arnold N, Auber B, Austin R, Azzollini J, Balmana J, Barbieri E, Bartram CR, Blanco A, Blumcke B, Bonache S, Bonanni B, Borg A, Bortesi B, Brunet J, Bruzzone C, Bucksch K, Cagnoli G, Caldes T, Caliebe $A$, et al. (2019). Large scale multifactorial likelihood quantitative analysis of BRCA1 and BRCA2 variants: An ENIGMA resource to support clinical variant classification. Hum Mutat 40(9): 1557-1578. doi: 10.1002/humu.23818

80. Starita LM, Ahituv N, Dunham MJ, Kitzman JO, Roth FP, Seelig G, Shendure J, Fowler DM (2017). Variant Interpretation: Functional Assays to the Rescue. Am J Hum Genet 101(3): 315-325. doi: 10.1016/j.ajhg.2017.07.014

81. Esposito D, Weile J, Shendure J, Starita LM, Papenfuss AT, Roth FP Fowler DM, Rubin AF (2019). MaveDB: an open-source platform to distribute and interpret data from multiplexed assays of variant effect. Genome Biol 20(1): 223. doi: 10.1186/s13059-019-1845-6

82. Gelman H, Dines JN, Berg J, Berger AH, Brnich S, Hisama FM, James RG, Rubin AF, Shendure J, Shirts B, Fowler DM, Starita LM (2019). Recommendations for the collection and use of multiplexed functional data for clinical variant interpretation. Genome Med 11(1): 85 . doi: 10.1186/s13073-019-0698-7

83. Starita LM, Young DL, Islam M, Kitzman JO, Gullingsrud J, Hause RJ, Fowler DM, Parvin JD, Shendure J, Fields S (2015). Massively Parallel Functional Analysis of BRCA1 RING Domain Variants. Genetics 200(2): 413-422. doi: 10.1534/genetics.115.175802

84. Mighell TL, Evans-Dutson S, O'Roak BJ (2018). A Saturation Mutagenesis Approach to Understanding PTEN Lipid Phosphatase Activity and Genotype-Phenotype Relationships. Am J Hum Genet 102(5): 943-955. doi: 10.1016/j.ajhg.2018.03.018

85. Chiasson M, Dunham MJ, Rettie AE, Fowler DM (2019). Applying Multiplex Assays to Understand Variation in Pharmacogenes. Clin Pharmacol Ther 106(2): 290-294. doi: 10.1002/cpt.1468

86. Findlay GM, Daza RM, Martin B, Zhang MD, Leith AP, Gasperini M, Janizek JD, Huang X, Starita LM, Shendure J (2018). Accurate classification of BRCA1 variants with saturation genome editing. Nature 562(7726): 217-222. doi: 10.1038/s41586-018-0461-z

87. Ikegami M, Kohsaka S, Ueno T, Momozawa $\mathrm{Y}$, Tamura K, Shimomura A, Hosoya N, Kobayashi H, Tanaka S, Mano H (2020). HighThroughput Functional Evaluation of BRCA2 Variants of Unknown Significance. bioRxiv: 2020.2001.2017.911057. doi: 10.1101/2020.01.17.911057 